\title{
Efficiency improvement opportunities for ceiling fans
}

\author{
Nihar Shah • Nakul Sathaye • Amol Phadke • \\ Virginie Letschert
}

Received: 26 April 2013 / Accepted: 11 June 2014 / Published online: 1 July 2014

(C) The Author(s) 2014. This article is published with open access at Springerlink.com

\begin{abstract}
Ceiling fans contribute significantly to residential electricity consumption, especially in developing countries with warm climates. This paper provides an analysis of costs and benefits of several options to improve the efficiency of ceiling fans to assess the global potential for electricity savings and green house gas (GHG) emission reductions. Ceiling fan efficiency can be cost-effectively improved by at least $50 \%$ using commercially available technology. If these efficiency improvements are implemented in all ceiling fans sold by $2020,70 \mathrm{TWh} /$ year could be saved and 25 million metric tons of carbon dioxide equivalent $\left(\mathrm{CO}_{2}\right.$-e) emissions per year could be avoided, globally. We assess how policies and programs such as standards, labels, and financial incentives can be used to accelerate the adoption of efficient ceiling fans in order to realize potential savings.
\end{abstract}

Keywords Ceiling fan · Energy efficiency · Standards · Labeling $\cdot$ Incentives $\cdot$ Market transformation

\section{Introduction}

This paper presents the results of an analysis of ceiling fan efficiency commissioned by the US Department of Energy and performed by the International Energy

N. Shah $(\varangle) \cdot$ N. Sathaye $\cdot$ A. Phadke $\cdot$ V. Letschert Energy Analysis Department, Environmental Energy Technologies Division, Lawrence Berkeley National Laboratory, 1 Cyclotron Rd., Berkeley, CA 94720, USA e-mail: nkshah@lbl.gov
Studies group at Lawrence Berkeley National Laboratory in support of the Super-efficient Equipment and Appliance Deployment (SEAD) initiative. ${ }^{1}$ SEAD aims to transform the global market by increasing the penetration of highly efficient equipment and appliances. The objective of this analysis is to provide the background technical information necessary to improve ceiling fan efficiency and support the voluntary activities of SEAD-participating countries.

Ceiling fans contribute significantly to residential electricity consumption in warm climates and especially in developing countries. For example, in India, ceiling fans alone accounted for approximately $6 \%$ of residential energy use in 2000. This figure is expected to grow to $9 \%$ in 2020 (De la Rue du Can et al. 2009), an increase that is equivalent to the energy output of 15 mid-sized power plants. ${ }^{2}$ In addition, ceiling fan

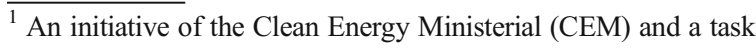
within the International Partnership for Energy Efficiency Cooperation (IPEEC), SEAD seeks to engage governments and the private sector to transform the global market for energy-efficient equipment and appliances. As of October 2012, the governments participating in SEAD are Australia, Brazil, Canada, the European Commission, France, Germany, India, Japan, Korea, Mexico, Russia, South Africa, Sweden, the United Arab Emirates, the UK, and the USA. More information on SEAD is available on its website at http://www.superefficient.org/.

${ }^{2}$ For this estimate, we assume an increase in BAU power consumption of $\sim 20 \mathrm{TWh}$. We also conservatively estimate that onetenth of ceiling fans are used during the peak hour and that a midsized power plant has a 500-MW capacity and runs at $70 \%$ efficiency (as described in Koomey et al. 2010). However, currently installed power plants in India have a much lower average efficiency (du Can et al. 2009).
} 
ownership rates have been shown to significantly increase in low-income Indian households as income levels increase (De la Rue du Can et al. 2009). Although ceiling fan standards and labeling programs are specified for every major economy in the world, these programs only discourage the use of highly inefficient fans (Waide and Harrington 2011). In developed countries and countries with milder climates, a smaller fraction of electricity consumption is attributable to ceiling fans. Nevertheless, ceiling fans account for as much as $5 \%$ of residential electricity use in the USA, although this varies greatly by region (Calwell and Horowitz 2001). Even in those areas where they do not constitute a significant fraction of electricity demand, ceiling fans can reduce energy consumption by reducing the use of other cooling devices.

This study assesses the potential for global ceiling fan energy-efficiency improvement. We analyze the cost-effectiveness of ceiling fan efficiency improvements while estimating the global potential for both energy consumption and $\mathrm{CO}_{2}$-e emission reductions. We utilize the Bottom-Up Energy Analysis System (BUENAS) to make these estimates (McNeil et al. 2012). First, we present a technological economic analysis of fan efficiency improvement options followed by global energy saving estimates. Finally, we discuss implications for the design of market transformation programs and conclude the paper.

\section{Technological-economic assessment of efficiency improvement options in ceiling fans}

Ceiling fan energy performance is typically measured in units of meters cubed per minute per watt $\left(\mathrm{m}^{3} / \mathrm{min} / \mathrm{W}\right)$. This represents the ratio of air delivery to power input. The term "efficiency" is commonly used to represent the ratio of mechanicaloutput to electrical-input power. In this paper, we follow the example of earlier studies (Chakraborty 2004). The term "efficacy" refers to fan performance, while the term "efficiency" is used as a general performance descriptor and when discussing the performance of motors.

Standards and labeling programs for ceiling fans are typically designed to ensure a specified level of efficacy. Specifications include subcategories that are classified by characteristics such as fan size, operating speed, or airflow. Fans have higher efficacy at lower speeds meaning standards and labeling programs categorize fans by operating speed (Chakraborty 2004). Fan efficacy can be increased through increasing blade length because power consumption decreases as blade length increases assuming constant airflow. Accordingly, some programs categorize fan standards and labels by fan size or sweep. Table 1 summarizes fan standards and labeling frameworks in various countries. In the USA, the ENERGY STAR program specifies minimum ceiling fan efficacy rankings for three different airflow levels (ENERGY 2012b). Similarly, the Indian standard IS-374 defines minimum efficacy levels for five different ceiling fan size categories (BIS 2007). In addition to this, the Indian Bureau of Energy Efficiency (BEE) maintains a star rating system based on fan efficacy (Singh et al. 2010). However, the Indian star rating system is applicable to only one size of fan $(1,200 \mathrm{~mm})$ and does not vary by fan speed.

\section{Efficiency improvement options for ceiling fan systems}

The ceiling fan system consists of multiple components that together determine the fan's overall energy consumption. We focus on engineering improvements that are easily quantifiable such as changes to fan motors and blades that improve ceiling fan efficiency.

\section{Fan motors}

Historically, ceiling fans have utilized AC induction motors because these motors are durable, easy to construct, and relatively inexpensive to manufacture. However, these AC induction fan motors are relatively inefficient because of the slip ${ }^{3}$ associated with single-phase induction motors. Brushless DC (BLDC) motors have become increasingly common in appliances in recent decades due to developments in electronic commutation and the availability of inexpensive and high-performing magnetic materials (Desroches and Garbesi 2011). Such motors are more efficient than brushed DC motors because they do not have the friction loss associated with mechanical commutation. Induction motors are

\footnotetext{
$\overline{3}$ The slip is the difference between the speed of the rotor and the magnetic field in an AC induction motor.
} 
Table 1 Summary of characteristics used in various standards and labeling programs

\begin{tabular}{|c|c|c|c|c|c|c|}
\hline \multirow{2}{*}{$\begin{array}{l}\text { Country } \\
\text { India }\end{array}$} & \multirow{2}{*}{$\frac{\text { Agency }}{\text { BIS }}$} & \multicolumn{2}{|c|}{ Standard/Label type } & \multirow[t]{2}{*}{ Speed } & \multirow{2}{*}{$\begin{array}{l}\text { Size category } \\
\text { Yes }\end{array}$} & \multirow{2}{*}{$\begin{array}{l}\text { Rating type } \\
\text { Specifies minimum efficacy for various fan sizes }\end{array}$} \\
\hline & & Standard & Voluntary & & & \\
\hline India & BEE & Label & Voluntary & & Only $1,200 \mathrm{~mm}$ & $\begin{array}{l}\text { Assigns star ratings to fans meeting minimum } \\
\text { efficacy requirements }\end{array}$ \\
\hline China & NDRC, AQSIQ & Standard & Mandatory & & Yes & $\begin{array}{l}\text { Assigns ratings based on efficacy, to fans classified } \\
\text { by size }\end{array}$ \\
\hline USA & EPA & Label & Voluntary & Yes & & $\begin{array}{l}\text { Specifies minimum efficacy for fans classified by } \\
\text { operating speed }\end{array}$ \\
\hline
\end{tabular}

Note: In Europe and India, the term "service value" is used to refer to efficacy.

inefficient because their rotors do not rotate synchronously with the magnetic field that induces rotor motion which results in slip. BLDC motors alleviate these issues because the rotor moves synchronously with the rotating $\mathrm{AC}$ magnetic field produced by electronic commutation. For instance, a $75-\mathrm{W}$ BLDC motor has been estimated to have an efficiency of up to about $90 \%$, whereas the average new $75-\mathrm{W}$ $\mathrm{AC}$ induction motor has an efficiency of around $75 \%$ (Desroches and Garbesi 2011). Table 2 shows this efficiency along with those of other 75-W motors.

Multiple engineering studies have estimated the potential for reducing energy consumption through the use of BLDC motors. One experimental Taiwanese study shows that the energy consumption of a ceiling fan with a BLDC motor is about $50 \%$ that of a fan with a splitphase induction motor (Liu et al. 2009).An experimental study from Australia shows that BLDC motors decreases ceiling fan energy consumption by a factor of three at low speeds and a factor of two at high speeds (Schmidt and Patterson 2001). Industry experts indicate that using a BLDC motor can reduce ceiling fan energy

Table 2 Efficiency data for various 75-W motor types in the USA

\begin{tabular}{ll}
\hline Motor type & Efficiency \\
\hline NovaTorque $^{\mathrm{a}}$ & $90 \%$ \\
Practical limits BLDC $^{6}$ & $87 \%$ \\
Practical limits AC induction & $84 \%$ \\
Average new production & $75 \%$ \\
Average installed base & $60 \%$ \\
\hline
\end{tabular}

Source: Desroches and Garbesi 2011

${ }^{a}$ The company NovaTorque has incorporated technical improvements to push efficiency further beyond the so-called practical limits of a BLDC motor. consumption by an estimated $60 \%$ in the USA (Parker and Hibbs 2010). In addition to the potential energy efficiency improvements achieved with BLDC motors, some fans in India incorporate a combination of elements that affect AC induction motor efficiency. These fans consume significantly less energy than normal. At high speeds, these fans can reduce power consumption from $70-75 \mathrm{~W}$ to about $45-50 \mathrm{~W}$. AC induction motor efficiency in these fans are increased with the amount of "active" material (such as lamination steel and copper), reduced air gap between the stator and rotor, and incorporation of standard-grade aluminum for die-cast rotors. ${ }^{4}$

\section{Fan blades}

Improving fan blade design has been shown to have a significant influence on fan efficiency. Efficiency improvements have been achieved by multiple approaches. For example, these include incorporation of aerodynamic attachments for conventional blades (Volk 1990), a decrease in the angle of attack through the use of twisted, tapered (TT) blades (Bird 2004), and use of TT blades with an air foil (Sonne and Parker 1998). We focus on the last of these options due to the wide use of this type of blade and the potentially large energy savings that are associated with this design. TT blades with an airfoil increase efficiency by reducing energy lost to turbulence and flow separation as discussed by Parker et al. (1999). Optimal blade design requires a balance between multiple objectives including maximization of air speed, uniform

\footnotetext{
${ }^{4}$ Note: This information including proprietary cost and technology data has been collected by the Prayas Energy Group in consultations with manufacturers and industry experts during the establishment of the Super Efficient Equipment Program (SEEP) for ceiling fans in India and shared with the authors confidentially (Prayas Energy Group 2012).
} 
air speed along the fan radius, and maximization of airflow coverage. A test of one such patented blade design indicates that the subject invention has an efficacy $86-111 \%$ higher than that of a conventional flat blade, indicating remarkable potential for energyefficiency improvements from changes in fan blade design (Parker et al. 2000). These blades can also be used to reduce motor size and cost, and the resulting device will still outperform a conventional fan. Some efficient blade designs have been adapted for aesthetic purposes to appear like traditional blades from the bottom side while being aerodynamic on the top side, thus improving efficiency 10-26\% when compared to conventional designs (Parker and Hibbs 2010). The blade has been designed to meet a market preference by some consumers for energy-efficient fans with a traditional appearance.

Fan efficiency improvement opportunities: empirical evidence from the US market

Figure 1 shows ENERGY STAR market data for qualifying fans being sold in the USA and Canada (ENERGY STAR 2012a and 2012b). The information regarding motor and blade type was obtained from product catalogs and from ceiling fan manufacturers producing fans with the highest efficacy, including Monte Carlo, Fanimation, Regency, and Emerson. The data in the figures are comparable to the performance of the most efficient fans being introduced in US and Canadian markets. For instance, the Emerson Midway
Eco fan is advertised as having a $75 \%$ reduction in energy consumption due to the Emerson EcoMotor ${ }^{\mathrm{TM}}$ (Emerson 2010).

The figure shows that fans with BLDC motors have far higher efficacy than the current ENERGY STAR high-speed standard requires $\left(2 \mathrm{~m}^{3} / \mathrm{min} / \mathrm{W}\right)$. These data indicate that engineering improvements, such as those previously discussed, can be used for purposes other than increasing efficacy. Other purposes include reducing motor size or material quality to reduce manufacturing costs in the absence of policy intervention to improve efficiency.

\section{Summary of efficiency improvement options}

Table 3 shows fan power consumption estimates resulting from various options from the preceding discussion.

As discussed earlier, actual reported efficacy improvements for the best blade designs are much higher than those summarized in Table 3. For the purposes of this study, we have assumed that blade design improvements will lead to relatively lower efficacy increases of 10-26 \% (Sonne and Parker 1998), implying a power consumption of between 55 and63 W, i.e., an approximately $15 \%$ improvement in power consumption from a $70-\mathrm{W}$ baseline. These lower efficacy improvement assumptions for fan blades are justified because (a) blade design has associated aesthetic and customer satisfaction trade-offs, (b) many high-efficiency blade designs are proprietary, and (c) the values assumed are a
Fig. 1 Efficacy for ENERGY

STAR ceiling fans (fan only, without lights) at high speed Source: ENERGY STAR (ENERGY STAR 2012a, ENERGY STAR 2012b) In 2010 and 2011, the market penetration of ENERGY STAR-qualified ceiling fans was 18 and $13 \%$, respectively, (ENERGY STAR 2012a, ENERGY STAR 2012b)

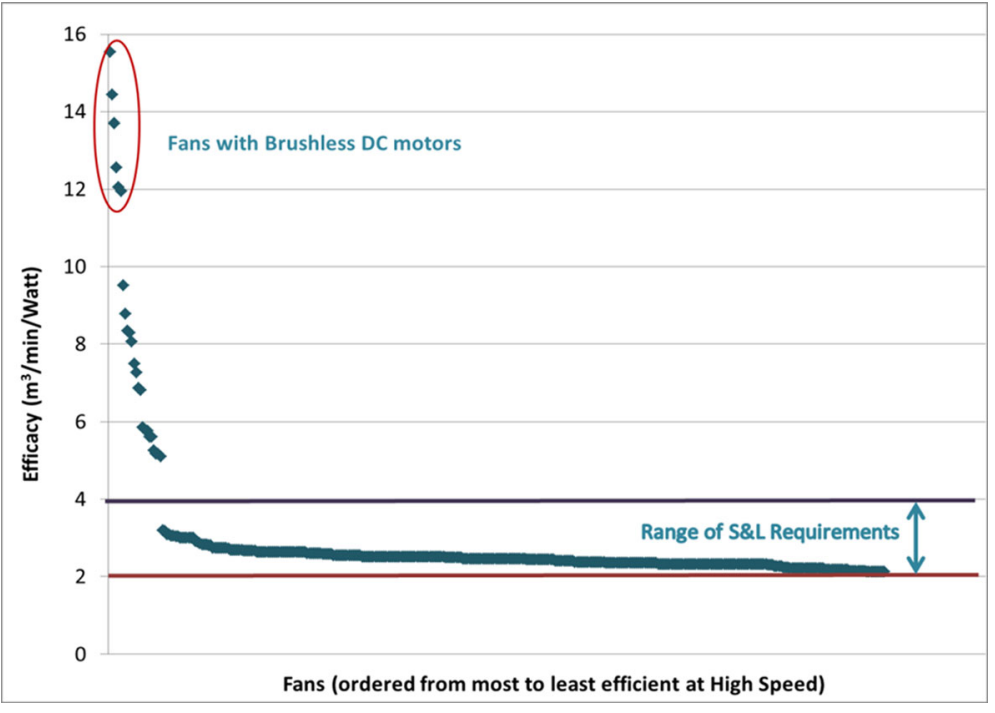


Table 3 Summary of power consumption of efficient fans using various options

\begin{tabular}{|c|c|c|c|c|}
\hline \multirow[t]{2}{*}{ Efficiency improvement option } & \multicolumn{2}{|c|}{ Efficient fan power consumption (W) } & \multirow{2}{*}{$\begin{array}{l}\text { Average power } \\
\text { savings (W) }\end{array}$} & \multirow{2}{*}{$\begin{array}{l}\text { Percent reduction } \\
\text { from baseline } \\
\text { power }\end{array}$} \\
\hline & $\begin{array}{l}\text { Prayas Energy } \\
\text { Group (2012) }\end{array}$ & $\begin{array}{l}\text { Sonne and } \\
\text { Parker (1998) }\end{array}$ & & \\
\hline Improved AC induction motor & $45-50$ & & 25 & $\sim 36$ \\
\hline BLDC motor & $30-35$ & & 35 & $\sim 50$ \\
\hline Efficient blades & & $55.5-63.6$ & 10.5 & $\sim 15$ \\
\hline
\end{tabular}

conservative estimate. The average efficiency improvement estimates shown in Table 3 are used below to estimate the cost-effectiveness of these options.

\section{Technical and economic analysis of efficiency improvement options}

Here, we estimate the costs of efficiency improvement of ceiling fans using the options previously described. We estimate the cost of conserved electricity (CCE) to assess the cost-effectiveness of these efficiency improvements. Due to data constraints, we only cite costs from a few countries while estimating the CCE.

\section{Fan motors}

Based on data collected from industry experts, we estimate the incremental cost of efficiency improvements of motors typically used in ceiling fans. We consider two types of efficiency improvement options. First, given that BLDC motors are significantly more efficient than induction motors, we estimate the incremental cost of BLDC motors of the same size and performance specifications over the typical induction motor. Second, we consider the cost of improving the efficiency of the induction motor itself, where the efficiency improvements are smaller and less costly compared to those achieved by a BLDC motor. BLDC motors are typically more expensive when compared to induction motors primarily because of the extra cost of the controller. Note that induction motors and BLDC motors have similar material costs (excluding the BLDC motor controller). This is primarily because the extra cost of permanent magnets in a BLDC motor is compensated by reduction in costs due to less copper and steel (See Chiang 2010; Desroches and Garbesi 2011 for a detailed discussion).Desroches and Garbesi find that the global cost of materials for a $750-\mathrm{W}$ induction motor (note: ceiling fan motors are typically much smaller, rated about $75 \mathrm{~W}$ ) is about US\$ 43.80, and for a BLDC motor, the material cost ranges from US\$ 24.20 to US\$ 36.74, as of 2011 (Desroches and Garbesi 2011). This indicates that the material cost of a smaller BLDC motor, such as what would be used in ceiling fans, should also range from a little less than to about equal to that of a comparable AC induction motor. Therefore, the incremental cost of the BLDC motor over an induction motor is essentially the cost of the controller. A BLDC motor controller is estimated to have a manufacturing cost between Indian rupees (INRs) 300-700 in India (Prayas Energy Group 2012). The same controller would cost between US\$ 3.2 to US\$ 22.5 in the USA (Chiang and Fairchild Semiconductor 2010). We assume the incremental cost of a BLDC motor that replaces a typical ceiling fan induction motor of $75 \mathrm{~W}$ to be approximately US $\$ 10.50$ for the purposes of this paper.

\section{Fan blades}

The cost of manufacturing efficient ceiling fan blades in the USA is estimated to be about US\$2.25, versus US\$ 0.25 per conventional flat blade (Parker and Hibbs 2010; Parker et al. 2000). The incremental cost of manufacturing an efficient blade versus a conventional blade in India is about INR 60 for three blades, i.e., US\$ 0.36 per blade. Although these appear to be significant cost increases for these components, they are not very large $(\sim 5 \%)$ compared to the total retail price of a ceiling fan. An important point to mention in the case of efficiency improvement through blade design is that blade design and manufacturing are driven by aesthetic considerations rather than just efficiency. This is also reflected in divergent estimates of the costs of manufacturing depending on the design, material, 
Table 4 Summary of reported manufacturing costs in dollars of efficiency improvement options
In converting from a per-blade to a total incremental cost, we assume that the fan has three blades.

\begin{tabular}{|c|c|c|c|c|c|}
\hline \multirow[t]{3}{*}{ Efficiency Improvement Option } & \multirow{2}{*}{\multicolumn{2}{|c|}{$\begin{array}{l}\text { India } \\
\text { Prayas Energy } \\
\text { Group (2012) }\end{array}$}} & \multicolumn{2}{|l|}{ USA } & \multirow[t]{3}{*}{ Average (\$) } \\
\hline & & & \multirow[t]{2}{*}{$\begin{array}{l}\text { Chiang } \\
(2010)\end{array}$} & \multirow[t]{2}{*}{$\begin{array}{l}\text { Parker and } \\
\text { Hibbs (2010) }\end{array}$} & \\
\hline & Low & High & & & \\
\hline Improved $\mathrm{AC}$ induction motor & $\$ 1.09$ & $\$ 1.82$ & & & $\$ 1.5$ \\
\hline BLDC motor & $\$ 5.45$ & $\$ 10.91$ & $\$ 3.2-\$ 22.5$ & & $\$ 10.5$ \\
\hline Efficient blades & $\$ 1.09$ & & & $\$ 6.00$ & $\$ 3.5$ \\
\hline
\end{tabular}

manufacturing, and treatment/finishing processes. The significance of aesthetic considerations in blade manufacture implies that mandating more efficient blades through minimum energy performance standards (MEPS) is not likely to be a practical or desirable option. However, given that some fans may be designed to meet energy efficiency policy specifications by using more efficient blades, it is still useful to estimate the costs of efficiency improvement through more efficient blades, particularly for labeling and incentive programs. Table 4 reports these costs in dollar terms along with average numbers, which are used as the input for the costeffectiveness calculation.

\section{Cost of conserved electricity}

This section presents the CCE in India for motor and blade improvements described above, using the efficiency assumptions discussed earlier along with corresponding cost assumptions. Two kinds of CCEs are calculated as follows: the manufacturing cost of conserved electricity $\left(\mathrm{CCE}_{\mathrm{m}}\right)$ which considers the incremental cost of the higher efficiency fan to the manufacturer and the cost to the consumer of conserved electricity $\left(\mathrm{CCE}_{\mathrm{c}}\right)$ which considers the incremental cost of the higher efficiency model to the consumer. The former metric $\left(\mathrm{CCE}_{\mathrm{m}}\right)$ is lower than the latter $\left(\mathrm{CCE}_{\mathrm{c}}\right)$ as it does not include markups or taxes. Therefore, $\mathrm{CCE}_{\mathrm{m}}$ can be used to measure the cost-effectiveness of a market transformation program, such as an upstream incentive program, while $\mathrm{CCE}_{\mathrm{c}}$ can be used to measure the cost-effectiveness of a standards program or a downstream incentive program.

As shown in Table 5 above, improved AC induction motors are the most cost effective single option, followed by BLDC motors. We also note that our cost and efficiency assumptions (and resulting CCE estimates) regarding efficiency improvement using more efficient blades are conservative and may very well be lower than those shown. This can be attributed to using cost and

Table 5 Cost of conserved electricity for various efficiency improvement options in India

\begin{tabular}{|c|c|c|c|c|c|}
\hline Efficiency improvement option ${ }^{a}$ & $\begin{array}{l}\text { Average power } \\
\text { savings (W) }\end{array}$ & $\begin{array}{l}\text { Percent reduction } \\
\text { from baseline power }\end{array}$ & $\begin{array}{l}\text { Average incremental } \\
\text { manufacturing cost }(\$)\end{array}$ & $\mathrm{CCE}_{\mathrm{m}}(\$ / \mathrm{kWh})$ & $\mathrm{CCE}_{\mathrm{c}}(\$ / \mathrm{kWh})$ \\
\hline Improved $\mathrm{AC}$ induction motor (A) & 25 & 36 & 1.5 & 0.003 & 0.005 \\
\hline BLDC motor $(\mathrm{B})$ & 35 & 50 & 10.5 & 0.014 & 0.027 \\
\hline Efficient blades (C) & 10 & 15 & 3.5 & 0.015 & 0.031 \\
\hline $\mathrm{A}+\mathrm{C}$ & 32 & 45 & 5.0 & 0.007 & 0.014 \\
\hline $\mathrm{B}+\mathrm{C}$ & 40 & 57 & 14.0 & 0.016 & 0.032 \\
\hline
\end{tabular}

We have assumed a 100\%markup in estimating costs to the consumer. Lifetime and hours of use assumptions are in line with Boegle (2010).

${ }^{a}$ Efficiency improvement options from single components (A, B, and C) are presented first followed by efficiency improvement options from combining two options $(\mathrm{A}+\mathrm{C}$ and $\mathrm{B}+\mathrm{C})$. The options are subsequently ordered by increasing cost of conserved energy. Also option $\mathrm{C}$, efficient blades can be used with both BLDC and AC motors. While BLDC motors and AC motors are widely available, efficient blades may be proprietary designs and also carry associated aesthetic trade-offs.

Assumptions: Lifetime $=10$ years; hours of use per day $=8.7$; discount rate $=7.6 \%$; multiplier for markup and taxes $=2.0$ 
Table 6 Cost of conserved electricity for various efficiency options in the SEAD economies and China

\begin{tabular}{|c|c|c|c|c|c|c|c|c|c|}
\hline \multirow[b]{2}{*}{ Economy } & \multirow[b]{2}{*}{ Discount rate } & \multirow[b]{2}{*}{$\begin{array}{l}\text { Baseline } \\
\text { UEC (kWh) }\end{array}$} & \multicolumn{2}{|c|}{$\begin{array}{l}\text { Efficient blades } \\
(15 \% \text { savings, } \$ 3.5 \\
\text { incremental cost })\end{array}$} & \multicolumn{2}{|c|}{$\begin{array}{l}\text { BLDC motor } \\
(50 \% \text { savings, } \$ 10.5 \\
\text { incremental cost) }\end{array}$} & \multicolumn{2}{|c|}{$\begin{array}{l}\text { Improved AC induction } \\
\text { motor ( } 36 \% \text { savings, } \\
\$ 1.5 \text { incremental cost) }\end{array}$} & \multirow[t]{2}{*}{$\begin{array}{l}\text { Representative } \\
\text { tariff } \\
(\$ / \mathrm{kWh})\end{array}$} \\
\hline & & & $\begin{array}{l}\text { CCEm } \\
(\$ / k W h)\end{array}$ & $\begin{array}{l}\text { CCEc } \\
(\$ / \mathrm{kWh})\end{array}$ & $\begin{array}{l}\text { CCEm } \\
(\$ / k W h)\end{array}$ & $\begin{array}{l}\text { CCEc } \\
(\$ / k W h)\end{array}$ & $\begin{array}{l}\text { CCEm } \\
(\$ / k W h)\end{array}$ & $\begin{array}{l}\text { CCEc } \\
(\$ / k W h)\end{array}$ & \\
\hline Australia & $3.11 \%$ & 21 & 0.13 & 0.26 & 0.12 & 0.24 & 0.023 & 0.047 & 0.10 \\
\hline Brazil & $11.58 \%$ & 88 & 0.05 & 0.09 & 0.04 & 0.08 & 0.008 & 0.016 & 0.19 \\
\hline Canada & $1.90 \%$ & 11 & 0.23 & 0.47 & 0.21 & 0.42 & 0.042 & 0.084 & 0.08 \\
\hline China & $1.63 \%$ & 75.3 & 0.03 & 0.07 & 0.03 & 0.06 & 0.006 & 0.012 & 0.19 \\
\hline EU & $6.63 \%$ & 11 & 0.30 & 0.59 & 0.27 & 0.53 & 0.053 & 0.106 & 0.19 \\
\hline India & $7.60 \%$ & 224 & 0.02 & 0.03 & 0.01 & 0.03 & 0.003 & 0.005 & 0.08 \\
\hline Indonesia & $1.12 \%$ & 150 & 0.02 & 0.03 & 0.01 & 0.03 & 0.003 & 0.006 & 0.09 \\
\hline Japan & $3.28 \%$ & 21 & 0.13 & 0.26 & 0.12 & 0.24 & 0.024 & 0.047 & 0.22 \\
\hline Korea & $4.19 \%$ & 21 & 0.14 & 0.28 & 0.12 & 0.25 & 0.025 & 0.049 & 0.07 \\
\hline Mexico & $3.81 \%$ & 88 & 0.03 & 0.06 & 0.03 & 0.06 & 0.006 & 0.012 & 0.08 \\
\hline Russia & $3.67 \%$ & 11 & 0.26 & 0.51 & 0.23 & 0.46 & 0.046 & 0.092 & 0.05 \\
\hline South Africa & $3.33 \%$ & 88 & 0.03 & 0.06 & 0.03 & 0.06 & 0.006 & 0.011 & 0.08 \\
\hline USA & $1.47 \%$ & 78.1 & 0.03 & 0.06 & 0.03 & 0.06 & 0.006 & 0.012 & 0.11 \\
\hline
\end{tabular}

efficiency estimates for more efficient blades with a traditional appearance as discussed earlier rather than the most efficient blades (Parker and Hibbs 2010). Also, data on blades indicated divergent estimates of the costs of manufacturing depending on design, material, manufacturing, and treatment/finishing processes, which varied due to aesthetic considerations. Given the globally traded nature, maturity, and high contribution of material costs to the total costs of the efficiency technologies considered, cost estimates based on the data in India and the USA are likely to be a reasonable approximation of the costs in other regions. To give a picture of cost-effectiveness under various scenarios, we also present the results of a sensitivity analysis on the CCE in the next section of this article.

The cost-effectiveness analysis for other regions presented in Table 6 takes into account regionspecific usage assumptions and discount rate estimates. The assumptions regarding usage are discussed in more detail later in the energy saving potential section. The assumptions regarding percent savings and incremental costs are the same as those presented earlier. This is a reasonable assumption because the percent saving numbers are the same for the same technology regardless of economy, but the costs of BLDC motors and AC induction motors are driven mainly by the cost of materials and electronics, which are part of the global market. The cost estimates for efficient blades are more uncertain because these blades may be based on proprietary designs, and blade design and manufacture are driven by aesthetic considerations rather than just efficiency. This is also reflected in divergent estimates of production costs depending on design, material, manufacturing, and treatment/finishing processes. Table 6 shows the estimate CCE for efficiency options in SEAD countries and China.

As can be seen in Table 6, improved AC induction motors are cost-effective in almost all economies, and BLDC motors and efficient blades are cost-effective in countries with higher fan usage (i.e., high unit energy consumption or UEC), such as Brazil, China, India, Indonesia, Mexico, South Africa, and the USA. Tariffs are assumed based on inputs used in LBNL's BUENAS model and in data collected by Shah et al. (2013). ${ }^{5}$

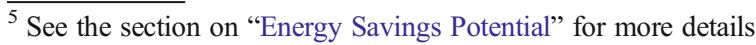
on the BUENAS model. http://www.superefficient.org/en/ Products/BUENAS.aspx
} 
Fig. 2 Sensitivity analysis of cost-effectiveness of incentive programs in India, assuming $50 \%$ power savings

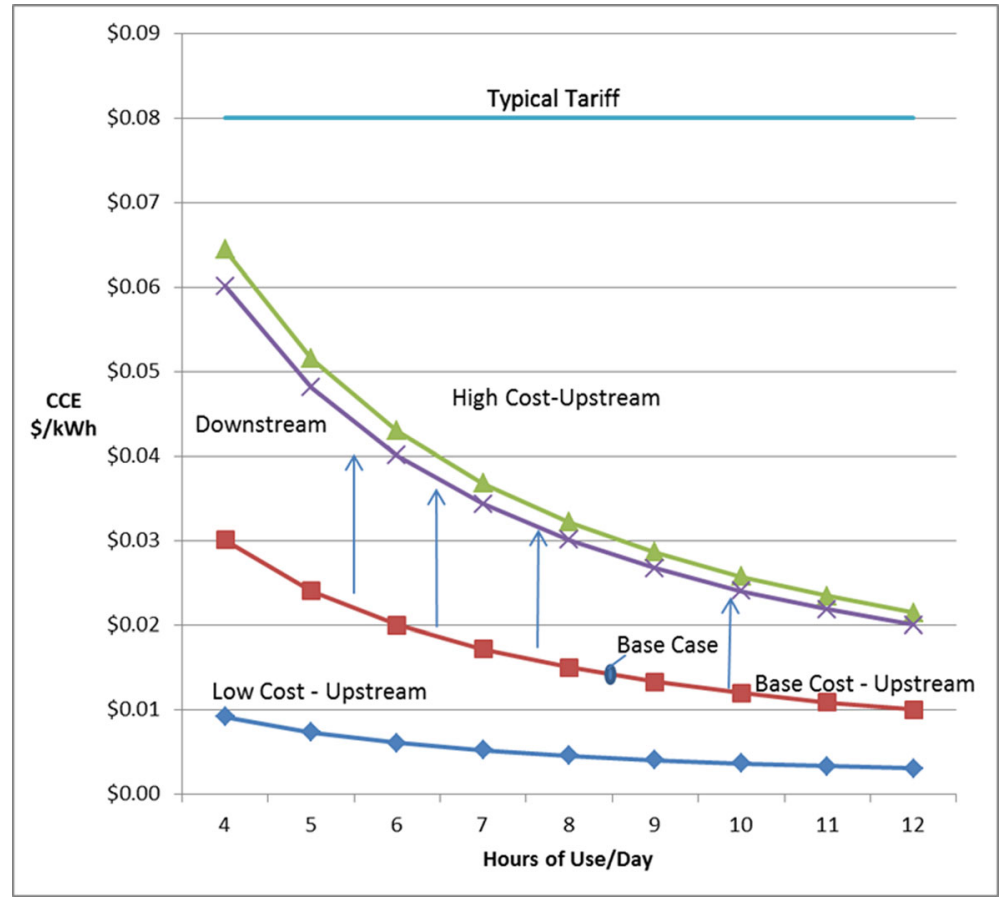

Sensitivity of cost-effectiveness analysis

To illustrate the cost-effectiveness of the options under varying assumptions for hours of use and cost, we present three scenarios that have different hours of use. We varied the costs of efficiency improvement from BLDC motors by calculating the $\mathrm{CCE}_{\mathrm{m}}$ using our high incremental cost estimate of $\$ 22.5$ in the "high cost" scenario and our low incremental cost of $\$ 3.2$ in the "low cost" scenario. These results are presented in Fig. 2, showing the CCE under the base-cost (\$10.5), low-cost (\$3.2), and high-cost (\$22.5) scenarios. These cost estimates are in-line with the high and low estimates reported by Chiang (2010). The range of hours of use per day (4-12 h) is consistent with Boegle et al. (2010), who identify that a lower range of use is $3-5 \mathrm{~h}$ per day and a higher range of use of $10-16 \mathrm{~h}$ per day. We also use the $\mathrm{CCE}_{\mathrm{c}}$ metric discussed earlier to show the estimated impact on cost-effectiveness of moving from an upstream program to a downstream incentive or standards program. This is represented as the curve labeled "downstream" in Fig. 2. A typical tariff for India is approximately 8 cents $/ \mathrm{kWh}(\sim 4.5 \mathrm{INR} / \mathrm{kWh})$.

The results in Fig. 2 show that, for improvements equivalent to the $50 \%$ savings in power consumption obtainable using a BLDC motor, an upstream incentive program for ceiling fans in India is cost-effective even assuming low hours of use and high incremental costs of efficiency improvement. Other countries with high ceiling fan usage (i.e., high UEC from ceiling fans) will also find these efficiency improvements cost-effective, as discussed earlier.

\section{Energy saving potential}

We used the BUENAS ${ }^{6}$ to estimate the potential global energy and $\mathrm{CO}_{2}$ emission savings from accelerated implementation of the engineering developments for ceiling fans described earlier. A detailed description of the methodology is available in (McNeil et al. 2012). This version of BUENAS covers 13 major economies, representing $80 \%$ of the world's total energy consumption. Our objective is to provide an approximate estimate for the potential savings from accelerated adoption of efficient fans. More precise estimates of the saving potential in each of the economies covered than those presented here will require significant further work in order to provide a more robust empirical basis for the assumptions used. Note that we have more robust data on India, China, and the USA compared to other

\footnotetext{
$\overline{{ }^{6} \mathrm{http}: / / \text { www.superefficient.org/en/Products/BUENAS.aspx }}$
} 
countries, and hence, the estimates of saving potential for these countries are likely to be more accurate than for the others.

\section{Data and methodology}

BUENAS is an end-use energy forecasting model designed to provide a detailed assessment of the potential for energy savings and green house gas GHG emission reductions from energy-efficiency standards and labeling programs worldwide (see McNeil et al. 2012 for a detailed description of the model). The model is "bottom-up" in that it calculates energy demand based on input data for individual appliance products. BUENAS is composed of three modules. The first calculates the number of appliances per household (diffusion) in a country at a given point in time, primarily based on an empirical relationship observed between appliance ownership and macroeconomic household variables such as household income. The second module estimates energy consumption and efficiency improvements at the appliance level. The third module is a stock turnover module that calculates the sales of appliances every year based on retirement of old units and increased penetration of appliances in households. This module combines the sales in every year with UEC to estimate the total stock energy consumption. The difference in stock energy consumption between a business as usual (BAU) and an efficiency case equals the savings. Energy savings are then converted into $\mathrm{CO}_{2}$ equivalent emission mitigation according to the power generation mix from each country.

\section{Results}

This section presents the BUENAS results in terms of stock energy consumption and global potential energy savings. BUENAS also provides $\mathrm{CO}_{2}$ emission mitigation potential calculated using country-specific carbon factors (McNeil et al. 2012).

\section{Efficiency scenario}

In the efficiency scenario, efficient fans with BLDC motors gradually enter the market, gaining $20 \%$ of market share starting in 2012. The market reaches saturation in 2017 when $100 \%$ of fans sold are assumed to be efficient. The UEC for efficient fans is assumed to be constant throughout the forecast period. We evaluate energy saving potentials in 2016, 2020, and 2030. Table 7. shows the results of the energy saving potential analysis, and Fig. 3 shows the corresponding $\mathrm{CO}_{2}$ emission results. India represents almost half of the potential electricity savings and $\mathrm{CO}_{2}$ emission mitigation potential in the economies covered in this analysis.
Table 7 Annual and cumulative energy saving forecasts

\begin{tabular}{|c|c|c|c|c|c|c|}
\hline \multirow[b]{2}{*}{ Year } & \multicolumn{3}{|c|}{ Annual electricity savings (TWh) } & \multicolumn{3}{|c|}{ Cumulative electricity savings (TWh) } \\
\hline & 2016 & 2020 & 2030 & $2012-2016$ & $2012-2020$ & $2012-2030$ \\
\hline Australia & 0.05 & 0.12 & 0.21 & 0.12 & 0.50 & 2.31 \\
\hline Brazil & 1.43 & 3.35 & 6.09 & 3.29 & 13.83 & 65.41 \\
\hline Canada & 0.05 & 0.11 & 0.19 & 0.11 & 0.46 & 2.08 \\
\hline China & 9.01 & 20.68 & 35.77 & 21.02 & 86.50 & 396.59 \\
\hline EU & 0.48 & 1.08 & 1.76 & 1.14 & 4.59 & 20.22 \\
\hline India & 14.17 & 33.54 & 62.38 & 32.52 & 137.91 & 660.60 \\
\hline Indonesia & 1.12 & 2.63 & 4.81 & 2.59 & 10.88 & 51.51 \\
\hline Japan & 0.24 & 0.54 & 0.84 & 0.56 & 2.27 & 9.90 \\
\hline Korea & 0.11 & 0.26 & 0.44 & 0.26 & 1.07 & 4.91 \\
\hline Mexico & 0.41 & 0.93 & 1.53 & 0.96 & 3.90 & 17.43 \\
\hline Russia & 0.15 & 0.34 & 0.52 & 0.37 & 1.46 & 6.19 \\
\hline South Africa & 0.17 & 0.40 & 0.65 & 0.40 & 1.67 & 7.46 \\
\hline USA & 2.43 & 5.65 & 9.86 & 5.61 & 23.47 & 108.57 \\
\hline Total & 29.82 & 69.62 & 125.05 & 68.94 & 288.51 & $1,353.19$ \\
\hline
\end{tabular}




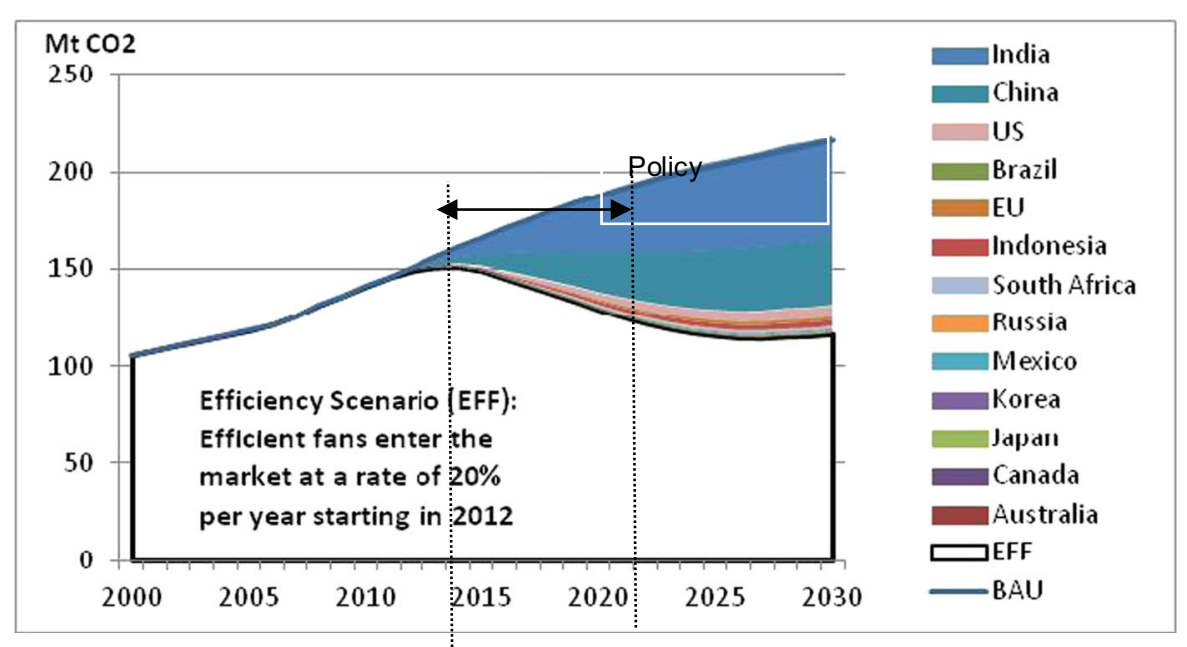

Fig. 3 Potential $\mathrm{CO}_{2}$ emission reductions resulting from introduction of efficient fans, 2000-2030

\section{Realizing cost-effective efficiency improvements: lessons for market transformation programs}

As discussed earlier in this paper, there are several costeffective options for the improvement of ceiling-fan efficiency that would reduce fan energy consumption by more than $50 \%$. Although highly efficient fans that incorporate most of the efficiency improvement options discussed in this paper are commercially available in certain countries (e.g., the USA), they constitute a very small percentage of sales. In some countries (e.g., India), fans with BLDC motors and efficient blades are not currently commercially available. Several barriers, including high purchase price and lack of information (e.g., lack of labels that recognize highly efficient performance), have been identified that contribute to the limited adoption of highly efficient fans (Singh et al. 2010). In this section, we discuss some broad insights for energy efficiency market transformation programs based on the earlier discussion.

\section{General insights}

Some of the insights that can be drawn from the preceding discussion apply across various types of market transformation programs and policies. We discuss some such general insights with respect to key fan characteristics such as fan size and speed, and with respect to blade design.

It is important for market transformation programs to classify fans by size and take into account the effect of fan speed on efficacy. First and foremost, size categories are important in market transformation programs to preclude the possibility that simply increasing blade length, without necessarily delivering better service, could circumvent a policy based merely on efficacy. For instance, although airflow increases with larger blades, the amount of cooling felt by the user may not. This is because the service delivered to the final user (in this case, cooling) depends not on the total volume of air moved but also on the velocity of the air. ${ }^{7}$ If market transformation policies classify fans by size, fan manufacturers will not be able to simply install longer blades to improve efficacy nominally without competing with other manufacturers in a separate size category or improving the service delivered to the final user. Second, operating speed is also an important criterion in designing market transformation programs because efficacy varies inversely with increasing fan speed (Davis Energy Group Energy Solutions 2004). This effect can be addressed either by using standard speed or minimum airflow in the test procedure for the program, such as in India's standard and labeling programs, or by changing the efficacy requirement at various speeds, such as in the ENERGY STAR program. It should be noted that the testing burden would be lower in the first case, with a trade-off on the accuracy of the test procedure at various speeds.

The literature discussed earlier indicates that there is remarkable potential for energy-efficiency

\footnotetext{
${ }^{7}$ The coefficient of convective heat transfer of the human body depends on the velocity of the air.
} 
Fig. 4 BEE (India) star labels compared to estimates of potential ceiling fan efficacy. Note: The baseline efficacy value is based on the average values reported as "national player's models" presented in (Garg and Jose 2009). Incremental improvements correspond to those presented earlier. The efficacy level of the best available fan corresponds to the fan with the highest efficacy in Fig. 1

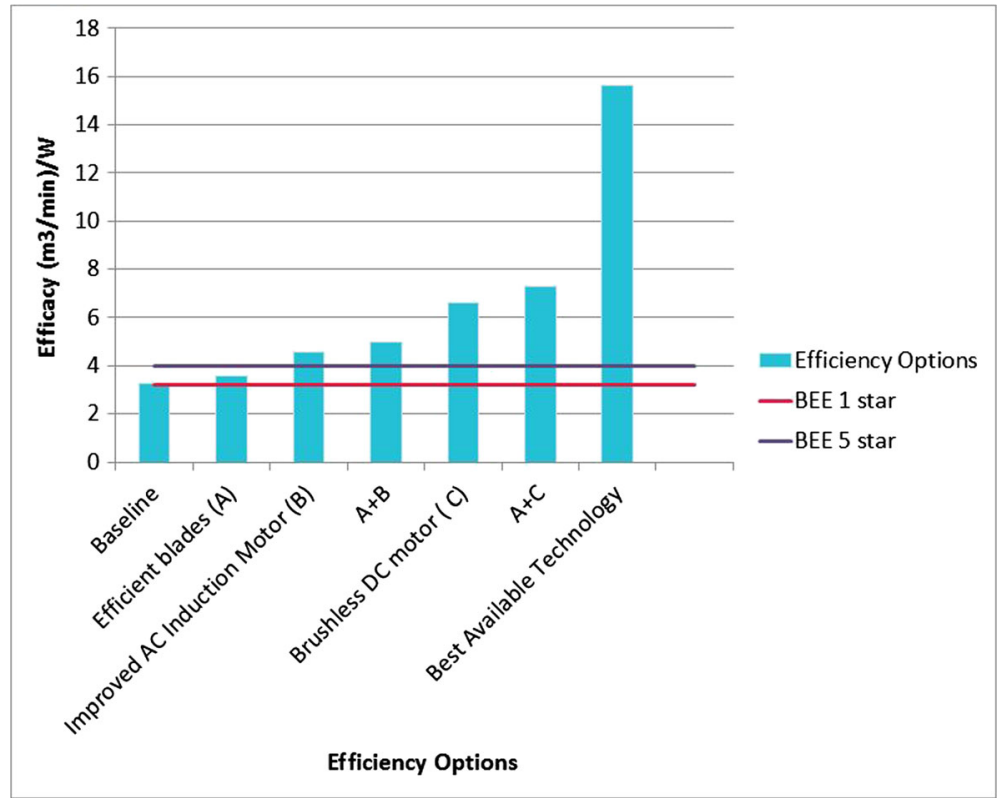

improvements from changes in fan blade design. We also find that blade design improvements have greater efficacy/power consumption saving impact at higher speeds. This implies that market transformation programs in economies with hotter climates and higher average airflows (e.g., India) will benefit proportionally more from blade design improvements than economies where average airflows tend to be lower (e.g., the USA). For example, the most efficient blade designs discussed in the literature will improve efficacy by $86 \%$ at lower speeds (airflows) versus $111 \%$ at higher speeds (airflows) compared with conventional blade designs (Parker and Hibbs 2010).

Standards and labeling programs

Efficiency levels specified by standards and labeling programs are far below what can be achieved by implementing cost-effective energy-efficiency options in ceiling fans (see Fig. 4). For example, as seen from data on the efficacy of fans meeting the US ENERGY STAR requirements, fans using BLDC motors and efficient blades are significantly more efficient (with efficacy as high as $15 \mathrm{~m}^{3} / \mathrm{min} / \mathrm{W}$ ) compared to the efficiency requirement for qualifying for ENERGY STAR (efficacy of $2.1-4.2 \mathrm{~m}^{3} / \mathrm{min} / \mathrm{W}$ ). Furthermore, the Indian BEE voluntary star rating program for fans only covered $2 \%$ of the Indian market, and only $18 \%$ of fans(without a light kit) on the US ceiling fan market were compliant with ENERGY STAR, indicating significant room for efficiency improvement (ENERGY ENERGY 2012a2a; PWC 2012).

These efficacy levels shown in Fig. 4 are tested under different conditions (notably airflow requirements/ speeds), so they cannot be directly compared against efficacy levels used by the standards or labeling programs in China, the EU, and the USA without accounting for this. ${ }^{8}$ However, the improvements in efficacy discussed in this paper are applicable across the range of commonly encountered airflows. This means that these improvements will offer significant energy savings of a similar order of magnitude regardless of airflow or test procedure alignment. For comparison, the US ENERGY STAR label has an efficacy requirement of $4.2\left(\mathrm{~m}^{3} / \mathrm{min} / \mathrm{W}\right)$ at low speeds and $2.1\left(\mathrm{~m}^{3} / \mathrm{min} / \mathrm{W}\right)$ at high speeds, while the lowest standard for efficacy in China varies by fan size from $3.47\left(\mathrm{~m}^{3} / \mathrm{min} / \mathrm{W}\right)$ for $1,800-\mathrm{mm}$ fans to $2.75\left(\mathrm{~m}^{3} / \mathrm{min} / \mathrm{W}\right)$ for $900-\mathrm{mm}$ fans (ENERGY 2012b; AQSIQ 2010). Figure 4 makes clear the significant potential for improvement in fan efficacy through increases in specified standards and labels.

\footnotetext{
${ }^{8}$ See Davis Energy Group (2004) for a discussion of the effect of fan speed and motor speed on efficacy. Increasing airflow from 5,000 CFM (the US high speed) to 7,415 CFM (i.e., $210 \mathrm{~m}^{3} / \mathrm{min}$, the minimum airflow for star-rated fans in India), i.e., a $48 \%$ increase will yield a decrease in efficacy of at most $35 \%$.
} 
The highest efficacy level recognized by labels in several countries is significantly lower than what can be achieved by adopting cost-effective efficiency options. Hence, current efficacy label levels need to be revised significantly to encourage deeper penetration of efficient ceiling fans at the top of the market with efficacy achievable using BLDC motors and efficient blades that are already on the market in the USA and that are cost-effective in other countries. The low penetration level of efficient ceiling fans in both India and the USA seems to indicate the presence of barriers to efficiency other than information, such as first cost, that may not be able to be addressed within a standards and labeling framework.

\section{Incentive programs}

Incentive programs for efficient fans could accelerate the penetration of superefficient fans for the following reasons. First, adoption of cost-effective efficient appliances is often hindered by high first cost, e.g., as discussed by Sathaye and Gupta (2010). In emerging economies, consumers are highly sensitive to high first costs (Singh et al. 2010). Second, due to the importance of aesthetics discussed earlier, it is not practical or desirable to mandate efficiency improvement from blade design through MEPS. However, the full existing potential from more efficient blades, as well as from BLDC motors, could be exploited through incentive programs for superefficient fans. Such programs could cost-effectively target efficacy of up to $15 \mathrm{~m}^{3} / \mathrm{min} / \mathrm{W}$, as discussed earlier. There are several examples of financial incentive programs that lower the first cost of costeffective energy-efficient appliances and equipment to accelerate their adoption. However, despite the large saving potential, financial incentive programs to promote the adoption of highly efficient fans are not common.

\section{Conclusions}

This paper presents an analysis of the potential for the improvement of ceiling fan components to reduce global energy consumption and GHG emissions. Improved blade design and $\mathrm{AC}$ induction motor materials, and the increased use of BLDC motors, are identified as costeffective options to improve the efficiency of ceiling fans. Adaptation of these technologies could provide ceiling fan power consumption savings of more than $50 \%$. Out of the several types of policies typically used to accelerate adoption of efficient products (e.g., awards, incentives, and standards and labeling programs), standards and labeling programs are the most commonly used to accelerate the market penetration of efficient fans.

Efficacy levels are tested under different conditions (notably airflow requirements/speeds) in various countries, so they cannot be directly compared against each other without accounting for this fact. Nevertheless, the improvements in efficacy discussed in this paper are applicable across the range of commonly encountered airflows, meaning that these improvements will offer significant energy savings of a similar order of magnitude regardless of airflow or test procedure alignment.

The highest efficacy level required by standards and labeling programs in several countries is significantly lower than what can be achieved by adopting the costeffective efficiency improvement options discussed here. Hence, current efficacy label levels need to be revised significantly to encourage deeper penetration of efficient ceiling fans at the top of the market.

The low penetration level of efficient ceiling fans in both India and the USA, even with labeling programs in place, ${ }^{9}$ seems to indicate the presence of barriers. These barriers to efficiency, in addition to information, such as first cost, may not be able to be addressed fully within a standards and labeling framework, particularly in emerging economies with price-sensitive consumers. However, despite the large saving potential, financial incentive programs that promote the adoption of highly efficient fans by removing the first cost barrier are not common.

One notable example under development is the SEEP in India where financial incentives will be provided to fan manufacturers to produce and sell highly efficient fans: fans that consume less than half of the energy consumed by fans typically sold on the Indian market (Singh et al. 2010). Even if the entire incremental cost of the highly efficient fans is covered by the financial incentives, the cost of the conserved electricity for efficiency improvements over $50 \%$ is just 0.7 rupees per kilowatt hour (US\$ $0.014 / \mathrm{kWh}$ ) which is about one

\footnotetext{
${ }^{9}$ BEE's voluntary star rating program for fans only covered $2 \%$ of the Indian market, while only $18 \%$ of the fans (without a light kit) on the US ceiling fan market were compliant with ENERGY STAR (ENERGY 2012a) indicating significant room for efficiency improvement.
} 
sixth of the cost of supplying electricity in India (Sathaye and Gupta 2010). SEEP or a similar upstream incentive program for ceiling fans would be costeffective even assuming higher costs and lower hours of use as discussed earlier. Therefore, there remains significant scope for improved policy design and implementation for aggressive and cost-effective ceiling fan efficiency improvements.

Acknowledgments This work was funded by the Bureau of Oceans and International Environmental and Scientific Affairs, US Department of State, and administered by the US Department of Energy in support of the SEAD initiative through the US Department of Energy under Contract No. DE-AC02-05CH11231.

Michael McNeil and Jing Ke of Lawrence Berkeley National Laboratory provided support for the BUENAS modeling effort. Daljit Singh and Adwait Pednekar of Prayas Energy Group provided a lot of the underlying data, as well as insights and comments on the draft article. Steve Pantano and P.K. Mukherjee at the Collaborative Labeling and Appliance Standards Program (CLASP), Abigail Daken at the US Environmental Protection Agency, Gabrielle Dreyfus at the US Department of Energy, Bonn Maguire of the Department of Climate Change and Energy Efficiency of Australia, and Won Young Park at the Lawrence Berkeley National Laboratory provided helpful comments and suggestions. Any errors or omissions are the authors' own.

Open Access This article is distributed under the terms of the Creative Commons Attribution License which permits any use, distribution, and reproduction in any medium, provided the original author(s) and the source are credited.

\section{References}

Bird, G. (2004). High efficiency ceiling fan. United States Patent Number 6733241.

Boegle, A., Singh, D. and Sant, G. (2010). Estimating technical energy saving potential from improving appliance efficiency in Indian households. In ACEEE summer study on energy efficiency in buildings: the climate for efficiency is now.

Bureau of Indian Standards. (2007). Indian Standard - specification for electric ceiling type fans and regulators (3rd Revision), Edition 4.6 (Incorporating Amendments No. 1-6).

Calwell, C., \& Horowitz, N. (2001). Ceiling fans: fulfilling the energy efficiency promise. Home Energy, 18(1), 24-30.

Chakraborty, A. (2004). Energy conservation in ceiling fans. In Proceedings of the 13th National Power Systems Conference, Chennai, India, pp. 835-838.

Chiang, J., Fairchild Semiconductor. (2010), Power point presentation, September 16. Available at: http://edg1.vcall.com/irwebsites/ fairchildsemi/Final $\% 20$-\%20PCIA.pdf.

Davis Energy Group Energy Solutions. (2004). "Codes and standards enhancement initiative for PY2004: title 20 standards development: analysis of standards options for ceiling fans."

Desroches, L.-B., and Garbesi, K. (2011). Max Tech and Beyond: maximizing appliance and equipment efficiency by design. Berkeley, CA: Lawrence Berkeley National Laboratory Report LBNL-4998E.

De la Rue du Can, Stephane, Virginie, E, Letschert, Michael A. McNeil, Nan Zhou, and Jayant, A. (2009). Sathaye. Residential and transport energy use in India: past trend and future outlook. LBNL.

Emerson Climate Technologies. (2010). Midway Eco, http://www. emersonfans.com/Pages/Fan.aspx?Fan=Midway $\% 20$ Eco Accessed 12/15/2010.

ENERGY STAR. (2012a). ENERGY STAR ceiling fan product list posted on November 14, 2012. http://www.energystar. gov/index.cfm?fuseaction=find_a_product.showProduct Groupandpgw_code $=\mathrm{CF}$.

ENERGY STAR. (2012b). ENERGY STAR unit shipment and market penetration report calendar year 2011 Summary. http://www.energystar.gov/ia/partners/downloads/unit_ shipment_data/2011_USD_Summary_Report.pdf.

Garg, S., and Jose, A. (2009). Energy efficiency labelling of ceiling fans in India: challenges and the way forward. Proceedings of the 5th International Conference on Energy Efficiency in Domestic Appliances and Lighting. http://www.enbook.pl/sites/default/files/ publikacje/150/20120130/energy_efficinency_in_ domestic_vol_3_p2.pdf.

General Administration of Quality Supervision Inspection and Quarantine of the People's Republic of China, (AQSIQ). (2010). Minimum allowable values of energy efficiency and energy efficiency grades of AC electric fans GB 12021.92008, Standardization Administration of the People's Republic of China.

Koomey, J. et al. (2010). Defining a standard metric for electricity savings. Environmental Research Letters, 5.

Liu, Chuan-Sheng, Jong-Chin, Hwang, Liang-Rui, Chen, Chih-Cheng, Fu. (2009). "Development of new structure of brushless DC servo motor for ceiling fan," Industrial Electronics and Applications, 2009. ICIEA 2009. 4th IEEE Conference on , vol., no., pp.2640,2643, 25-27 May.

McNeil, M., Letschert, V., de la Rue du Can, S., and Ke, J. (2012). Bottom-up energy analysis system - methodology and results. Berkeley CA: Lawrence Berkeley National Laboratory Report LBNL 5722E.

Parker, D, and Hibbs, B. (2010), Efficient traditionally appearing ceiling fan blades with aerodynamical upper surfaces. United States Patent Number 7665967.

Parker, D., Callahan, M., Sonne J., and Su, G. (1999). Development of a high efficiency ceiling fan "the gossamer wind." Tallahassee, FL: Florida Energy Office, Department of Community Affairs.

Parker, D., Hua, G., and Hibbs, B. (2000). High efficiency ceiling fan. United States Patent Number 6039541.

Prayas Energy Group, (2012). Singh G, Sant G, Chunekar A, Pednekar A and Dixit S, Development of SuperEfficient Equipment Program (SEEP) for fans, Available at: http://www.prayaspune.org/peg/ publications/item/175.html.

Sathaye, J., and Gupta, A. (2010). Eliminating electricity deficit through energy efficiency in India: an 
evaluation of aggregate economic and carbon benefits. Berkeley CA: Lawrence Berkeley National Laboratory Report LBNL-3381E.

Schmidt, K., \& Patterson, D. (2001). Performance results for a high efficiency tropical ceiling fan and comparisons with conventional fans: Demand side management via small appliance efficiency. Renewable Energy, 22(1-3), 169-176.

Shah, N., Waide, P., and Phadke, A. (2013). Cooling the planet: opportunities for deployment of superefficient room air conditioners, Lawrence Berkeley National Laboratory and Navigant Consulting Report, LBNL $6164 E$, available at:http://superefficient.org/en/ Activities/Technical\%20Analysis/ /media/Files/Final\% 20SEAD\%20Room\%20AC\%20Report.pdf.
Singh, D., Barve, A., and Sant, G. (2010).Ceiling fan the overlooked appliance in energy efficiency discussions. Pune, India: Prayas Energy Group.

Sonne, J., and Parker, D. (1998). Measured ceiling fan performance and usage patterns: implications for efficiency and comfort improvement. In Proceedings of ACEEE Summer Study on Energy Efficiency in Buildings: Energy Efficiency in a Competitive Environment, pp.335-341.

Volk, S. (1990). Propeller breeze enhancing blades for conventional ceiling fans. United States Patent Number 4892460.

Waide, P., and Harrington, L. (2011). Opportunities for success and $\mathrm{CO}_{2}$ savings from appliance energy efficiency harmonisation. Navigant Consulting in Partnership with CLASP. Available at: http://www.clasponline.org/clasp. online.resource.php?disdoc=781\#opportunities. 